are successful doctors may then be prepared to invest more time in them. Further consideration should be given to new ways that general practitioners can deliver and follow up lifestyle interventions, including implementing the process of change model and undertaking motivational interviewing. The role of practice nurses, health visitors, and specialist clinics may be important in enhancing a general practitioner's initial intervention.

I am grateful to Dr Peter Anderson for commenting on a draft of this article.

1 Blot W. Alcohol and cancer. Cancer Res 1992;52 (suppl):2119-23S

2 Cancer Research Campaign. Factsheet 14: oral cancer. London: CRC, 1993.

3 Secretary of State for Health. Health of the Nacion: a strategy for health in England. London: HMSO, 1992. (Cm 1986.)

4 Anderson P. Reducing alcohol consumption. In: Fowler G, Anderson P, Gray $\mathrm{M}$, eds. Prevention in general practice. Oxford: Oxford University Press, 1993:136-47.

5 Anderson P. Effectiveness of general practice interventions for patients with harmful alcohol consumption. Br f Gen Pract 1993;43:386-9.

\section{Selected additional references}

Anderson P. Alcohol as a key area. $B M 7$ 1991;303:766-9.

Anderson P. The interaction between research and policy-alcohol and general practice in the United Kingdom. Addiction 1993;88:1215-75.

Anderson P. Population and high-risk approaches both necessary to reduce population harm. Addiction 1993;88:170-4.

Anderson P, Cremona A, Paton A, Turner C, Wallace P. The risk of alcohol. Addiction 1993;88:1493-508.

Anderson P, Wallace P, Jones H. Alcohol problems: practical guides for general Anderson P, Walace P, Jones H. Alcohol
practice. Oxford: Oxford University Press, 1988.

practice. Oxford: Oxford University Press, 1988 .
Andserson $\mathrm{P}$, Scotr $\mathrm{E}$. The effect of general practitioners advice to heavy Andserson $P$, Scott $\mathrm{E}$. The effect of $\mathrm{g}$
drinking men. $B ; \tilde{F}$ Addict 1992;87:891-900.

drinking men. Br $\mathcal{f}$ Addict 1992;87:891-900.
Babor TF, Grant M. WHO Collaborating Investigators Project on identification Babor TF, Grant $\mathrm{M}$. WHO Collaborating Investigalors Project on identification
and management of alcohol related problems. Combined analyses of outcome dara: the coss national generalizability of brief interventions. Report on phase II: a randomised clinical trial of brief interventions in primary care. Copenhagen: WHO, 1992.

Bien TH, Miller WR, Tonigan JS. Brief interventions for alcohol problems: review. Addiction 1993;88:315-36.
Doll R. The prevention of cancer: opportunities and challenges. In: Heller T, Davey B, Bailey $\mathrm{L}$, eds. Reducing the risk of cancers. London: Hodder and Stoughton, 1989:14-25.

Effective Health Care. Brief interventions and alcohol use. Nuffield Instirute for Health, University of Leeds; Centre for Health Economics, University of York; Research Unit, Royal College of Physicians, 1993.

Health Education Authority. Cut down on your drinking pack. London: HEA, 1991.

International Agency for Research on Cancer. IARC monographs on the evaluation of carinogenic risks to humans; alcohol drinking. Lyons: 1ARC, 1988. Medical Council on Alcoholism. Hazardous drinking: a handbook for general practitioners. Lordon: MCA, 1987.

Office of Population Censuses and Surveys. General household survey 1992. London: HMSO, 1994.

Prochaska J, DiClemente $\mathrm{C}$. Toward a comprehensive model of change. In: Miller WR, Heather $\mathbf{N}$, eds. Treating addictive behaviors: processes of change. New $\bar{C}$ York: Plenum, 1986:3-27.

Rollnick S, Heather N, Gold R, Hall W. Development of a short "readiness to chang" questionnaire for use in brief, opportunistic in to change questonnaire for use in bref, oppon Royal College of General Practitioners. Alcohol-a balanced view. London: $\frac{\varrho}{20}$
RCGP, 1986. Royal College of General Practitioners. Alcohol and drags. London: RCGP, 1991.

Royal College of Physicians. The medical consequences of alcohol abuse: a great and growing evil. London: Tavistock, 1987

Reid ALA, Webb GR, Hennrikus D, Fahey PP, Sanson-Fisher RW. Detection of parients with high alcohol intake by general practitioners. $B M F$ 1986;293: 735-7.

Rose G, Day $\mathrm{S}$. The population mean predicts the number of deviant individuals. BMY 1990;301:1031-4.

individuals. $B M Y 1$ 1990;301:1031-4.
Saunders JB, Aasland OG, Babor TF, De La Fuente JR, Grant M. Development Saunders JB, Aasland OG, Babor TF, De La Fuente JR, Grant M. Development $\infty$
of the alcohol use disorders identification test (AUDIT): WHO Collaborative Project on Early Detection of Persons with Harmful Alcohol Consumption-II. Addiction 1993;88:791-804.

Scott E, Anderson P. Randomised controlled trial of general pracritioners intervention in women with excessive alcohol consumption. Drug and Alcohol $\overrightarrow{\mathrm{G}}$ Review 1990;10:313-2.

Wallace $P$, Cutler $S$, Haines A Randomised controlled trial of general $N$ practicioners intervencion in patients with excessive alcohol consumption. $B M 7$ 음 1988:297:663-8.

Wallace $P$, Haines $A$. The use of a questionnaire in general practice to increase $\vec{Z}$ the recognition of patients with excessive alcohol consumption. BMF 1985;290: 1949-53.

A complete list of references can be obtained from the author.

Statistics Notes

\title{
Diagnostic tests 1: sensitivity and specificity
}

\author{
Douglas G Altman, J Martin Bland
}

This is the third in a series of occasional notes on medical statistics.

\section{Medical Statistics \\ Laboratory, Imperial Cancer Research Fund, London WC2A 3PX Douglas G Altman, head}

Department of Public Health Sciences, St George's Hospital Medical School, London SW17 ORE

$\mathrm{J}$ Martin Bland, reader in medical statistics
The simplest diagnostic test is one where the results of an investigation, such as an $x$ ray examination or biopsy, are used to classify patients into two groups according to the presence or absence of a symptom or sign. For example, the table shows the relation between the results of a test, a liver scan, and the correct diagnosis based on either necropsy, biopsy, or surgical inspection. ' How good is the liver scan at diagnosis of abnormal pathology?

Relation between results of liver scan and correct diagnosis ${ }^{2}$

\begin{tabular}{lccc}
\hline & \multicolumn{3}{c}{ Pathology } \\
\cline { 2 - 4 } Liver scan & $\begin{array}{c}\text { Abnormal } \\
(+)\end{array}$ & $\begin{array}{c}\text { Normal } \\
(-)\end{array}$ & Total \\
\hline Abnormal (+) & 231 & 32 & 263 \\
Normal $(-)$ & 27 & 54 & 81 \\
\hline Total & 258 & 86 & 344 \\
\hline
\end{tabular}

One approach is to calculate the proportions of patients with normal and abnormal liver scans who are correctly "diagnosed" by the scan. The terms positive and negative are used to refer to the presence or absence of the condition of interest, here abnormal pathology. Thus there are 258 true positives and 86 true negatives. The proportions of these two groups that were correctly diagnosed by the scan were 8 $231 / 258=0.90$ and $54 / 86=0.63$ respectively. These two proportions have confusingly similar names.

Sensitivity is the proportion of true positives that are correctly identified by the test.

Specificity is the proportion of true negatives that are $\frac{D}{0}$ correctly identified by the test.

We can thus say that, based on the sample studied, $\tilde{N}$ we would expect $90 \%$ of patients with abnormal $\omega$ pathology to have abnormal (positive) liver scans, 을 while $63 \%$ of those with normal pathology would haveco normal (negative) liver scans.

The sensitivity and specificity are proportions, so $\stackrel{\circ}{+}$ confidence intervals can be calculated for them using $\underline{T}$ standard methods for proportions. ${ }^{2}$

Sensitivity and specificity are one approach to $\stackrel{\oplus}{\mathscr{Q}}$

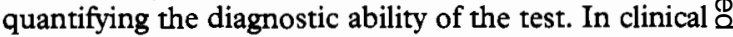
practice, however, the test result is all that is known, so we want to know how good the test is at predicting 8 abnormality. In other words, what proportion of patients with abnormal test results are truly abnormal? This question is addressed in a subsequent note.

1 Drum DE, Christacapoulos JS. Hepatic scintigraphy in clinical decision making. I Nucl Med 1972;13:908-15.

2 Gardner MJ, Altman DG. Calculating confidence intervals for proportions and their differences. In: Gardner MJ, Altman DG, eds. Statistics with confidence. London: BMJ Publishing Group, 1989: 28-33. 